\title{
Sport participation in Victoria, 2018 Research summary \\ Part 1: Key findings at a glance
}

This summary outlines key findings and insights into community sport participation in Victoria across ten popular sports detailed below in Figure 1. Now in its fourth year, this research, conducted jointly by VicHealth and Sport and Recreation Victoria, compares participation across age, sex and region in 2018 and compared to 2015.

\section{Part 1 contents}

1.1 Organised sport participation in Victoria, 2018

1.2 Organised sport participation in Victoria in 2018 compared to 2015

1.3 Organised sport retention from 2015-2018

1.4 Regional and local government snapshot

Part 2: Discussion of key findings provides more detailed discussion and recommendations and can be found here.

Figure 1. Sports included in the VicHealth and Sport and Recreation Victoria research

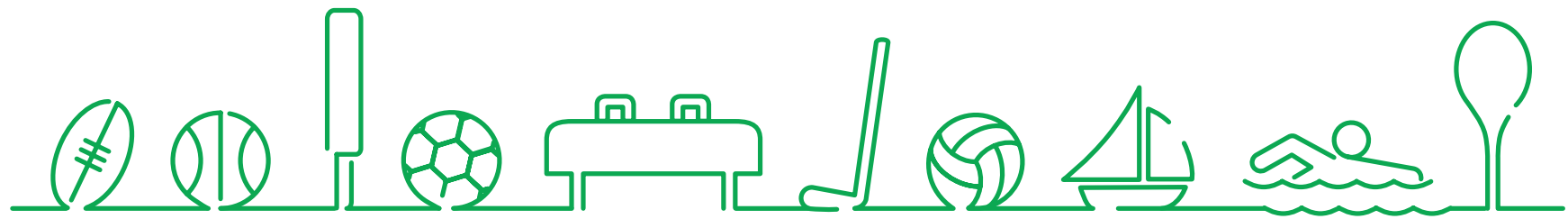

Please note: golf and bowls did not provide data for 2018 and are not included

\subsection{Organised sport participation in Victoria, 2018}

Over half of all sport participants are aged between $4-14$ years.

Sport participation is highest among children and adolescents aged 10-14 years and drops significantly during late adolescence 15-19 years.
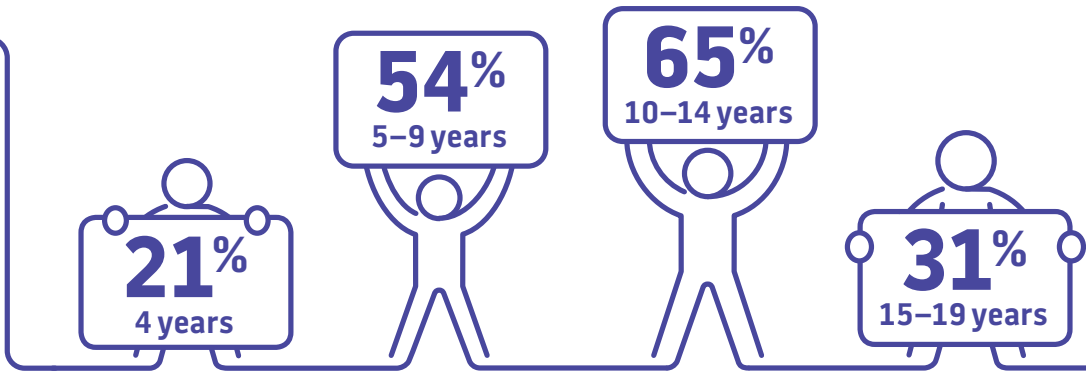

Sport participation rates among females are just over half of those among males.

\section{Sport participation rates are} higher in regional Victoria compared to metropolitan Melbourne. Metropolitan - growth areas also have significantly lower sport participation rates than all other regions.
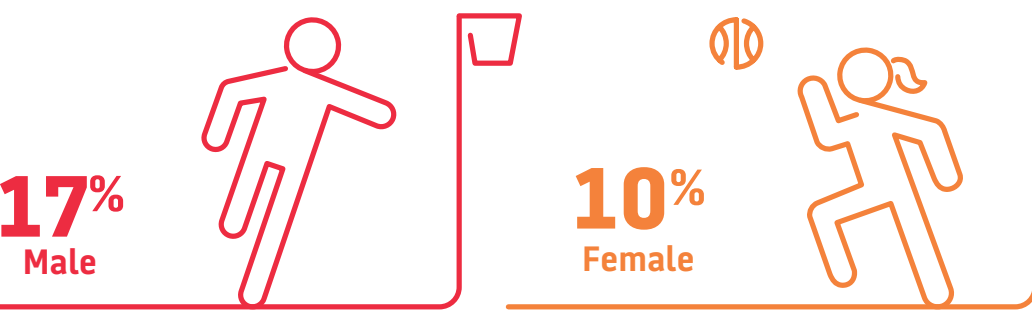

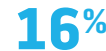

Regional Victoria

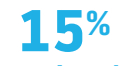

Regional - growth

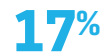

Regional - other
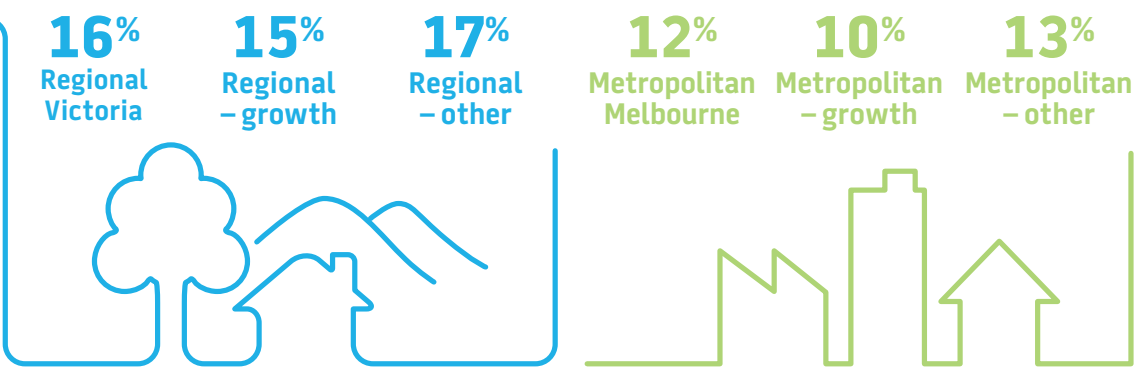

Participation data collection of sporting organisations can significantly fluctuate in quality both across sports and in the same sport from year to year. In the year following implementation of a new participant database, sports data can be of lower quality.

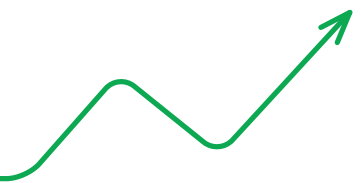




\subsection{Organised sport participation in 2018 compared to 2015}

1. Participation in sport increased by more than 95,900 participants $(0.8 \%$ increase in the participation rate) between 2015-2018. The participation increase was higher for females ( $1 \%)$ than for males $(0.4 \%)$.

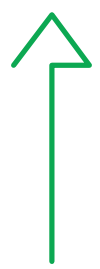

\section{4 sports}

2. Four sports had an increased participation rate.

- The overall participation numbers increased from 2015 to 2018 , with 95,954 more sports participants in 2018 compared to 2015. This corresponds to a participation rate increase of $0.8 \%$.

- The largest growth in participation rates 2015-2018 were within the 10-14-year age group with an increase of $2.7 \%$, followed by 15-19 years with an increase of $1.9 \%$.

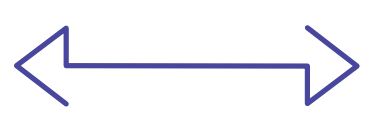

\section{5 sports}

3. Five sports had the same participation rate and one sport had a decreased participation rate.

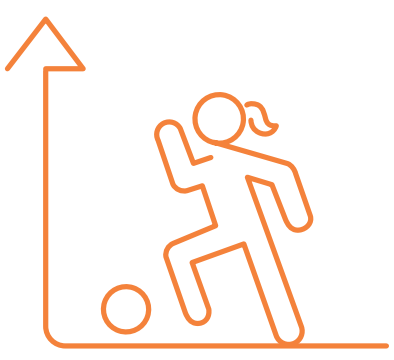

4. Six sports had an increased participation rate for females.

- The largest growth in participation rate for females were within the 10-14-year age group with an increase of $6.2 \%$, followed by the 5-9-year age group with an increase of $5.9 \%$. Participation increased in all female age groups (below 85 years of age).

- The increase in participation for females was largely due to increases in participation in traditionally male dominated sports such as Australian football, cricket and soccer.

- Four sports hada decreased participation rate for females.

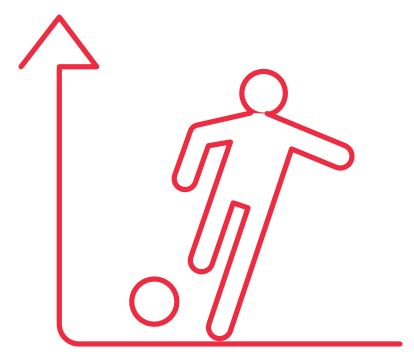

5. Six sports had an increased participation rate for males.

- The largest growth in participation rate for males were within the 15-19-year age group with an increase of $2.3 \%$. There was a decrease of $3.9 \%$ for the 5-9-year age group.

- Four sportshada decreased participation rate for males 


\subsection{Organised sport retention from 2015 to 2018}

From 2015-2018, 16\% of participants played their sport for each of the four years, and nearly half (48\%) played only one year, $21 \%$ played two years and $16 \%$ played three years.

\section{$48 \%$}

Participation for one of the four years

\section{Participation for three} of the four years
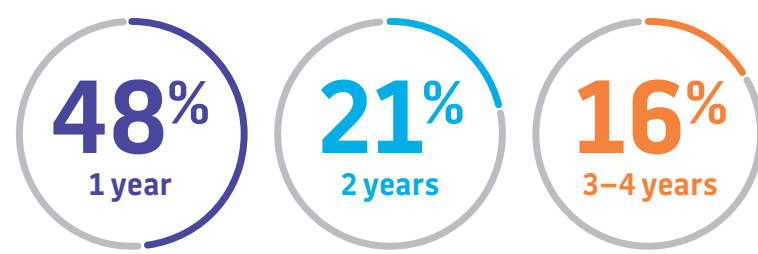

Nearly half of all participants (48\%) played for one year only from 2015 to 2018 , with $21 \%$ playing two years, while those playing three or four years was $16 \%$ each.

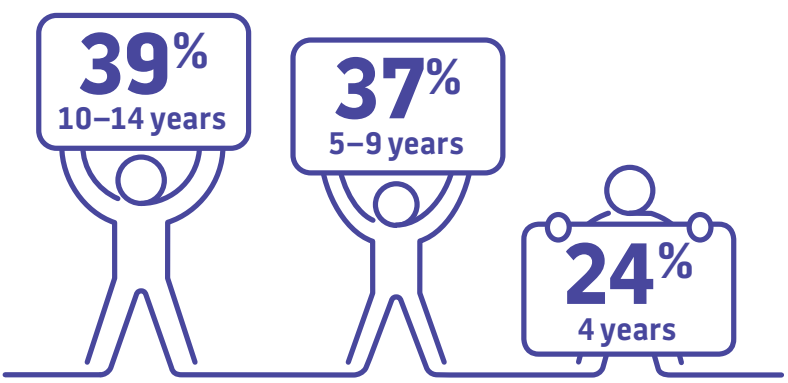

The highest age of retention over all four years was for those aged 10-14 (39\%), followed by 5-9 years (37\%). Less than a quarter of participants (24\%) aged four in 2015 played continually for four years. For these ages, retention was slightly higher for males compared to females.
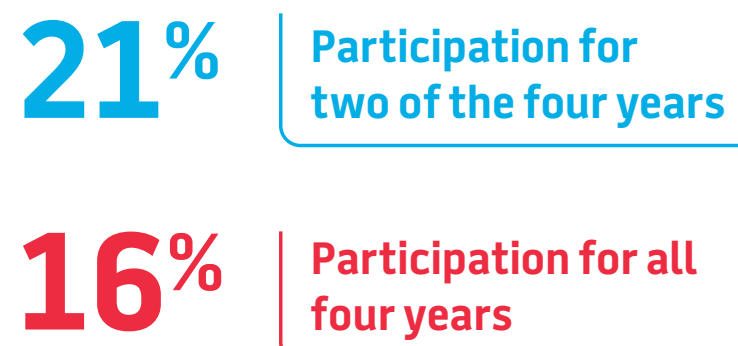

Participation for all four years

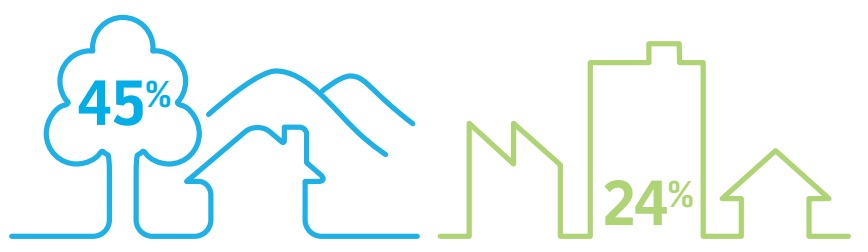

The highest retention over all four years was $45 \%$ in the Gunnawarra Shire, in Regional - other. The lowest retention over the four years was for the City of Melbourne (24\%), in Metropolitan - other.

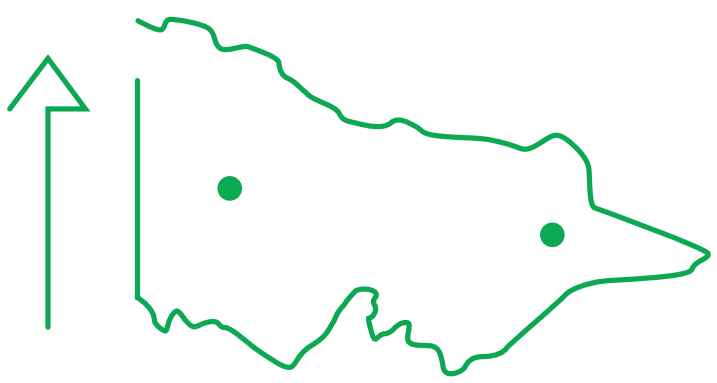

There was generally higher retention in the western areas of Victoria, and in the outer eastern Metropolitan LGAs. 


\subsection{Regional and local government snapshot}

There is considerable variation in overall participation rates in these sports across local government areas (Table 1). An understanding of how participation rates differ can inform local planning for facilities, programs and overall approach to increasing physical activity.

However, this information should be considered in conjunction with other available data to build a total picture of the needs of the community. Lower participation rates do not necessarily mean the area has lower overall physical activity levels. It may mean, for instance, that there is a lack of sporting facilities and instead the community has higher rates of walking, cycling or other active recreation.

\section{Organised sport participation in Victoria, 2018}

- The highest overall sport participation rate was 31\% in Buloke Shire, in the Regional - other area. This highest participation rates in the other areas were: Regional - growth: Surf Coast, 23\%; Metropolitan - other: Nillumbik, 24\%; and Metropolitan - growth: Cardinia, $14 \%$.

- The lowest participation rate was 5\% in Greater Dandenong, in Metropolitan - other. The lowest participation rates in the other regions were: Metropolitan - growth: Melton, 8\%; Regional - other: Hepburn, 12\%; and Regional - growth: Ballarat $14 \%$.

- The highest participation rate for females was $72 \%$ for 10-14-year olds, within Regional - other, followed by $61 \%$ in Regional - growth and 61\% of Metropolitan - other, but only $32 \%$ for Metropolitan - growth.

\section{Organised sport participation in 2018 compared to 2015}

- The region with highest participation growth was Regional growth with an overall increase of $2 \%, 2015-2018$. Regional - growth had an increase of $11 \%$ for females aged 5-9 and a $10 \%$ increase for females aged $10-14$ years.

- Metropolitan - growth had an overall decrease of 0.1\%.

- Within the regional LGAs, there was generally higher participation in the north-west and south-west compared to the eastern regions of Victoria.

- Within the metropolitan LGAs, there was generally higher participation in the eastern regions compared to western suburbs. 
Figure 2: Participation rate, by LGA in regional Victoria, 2018

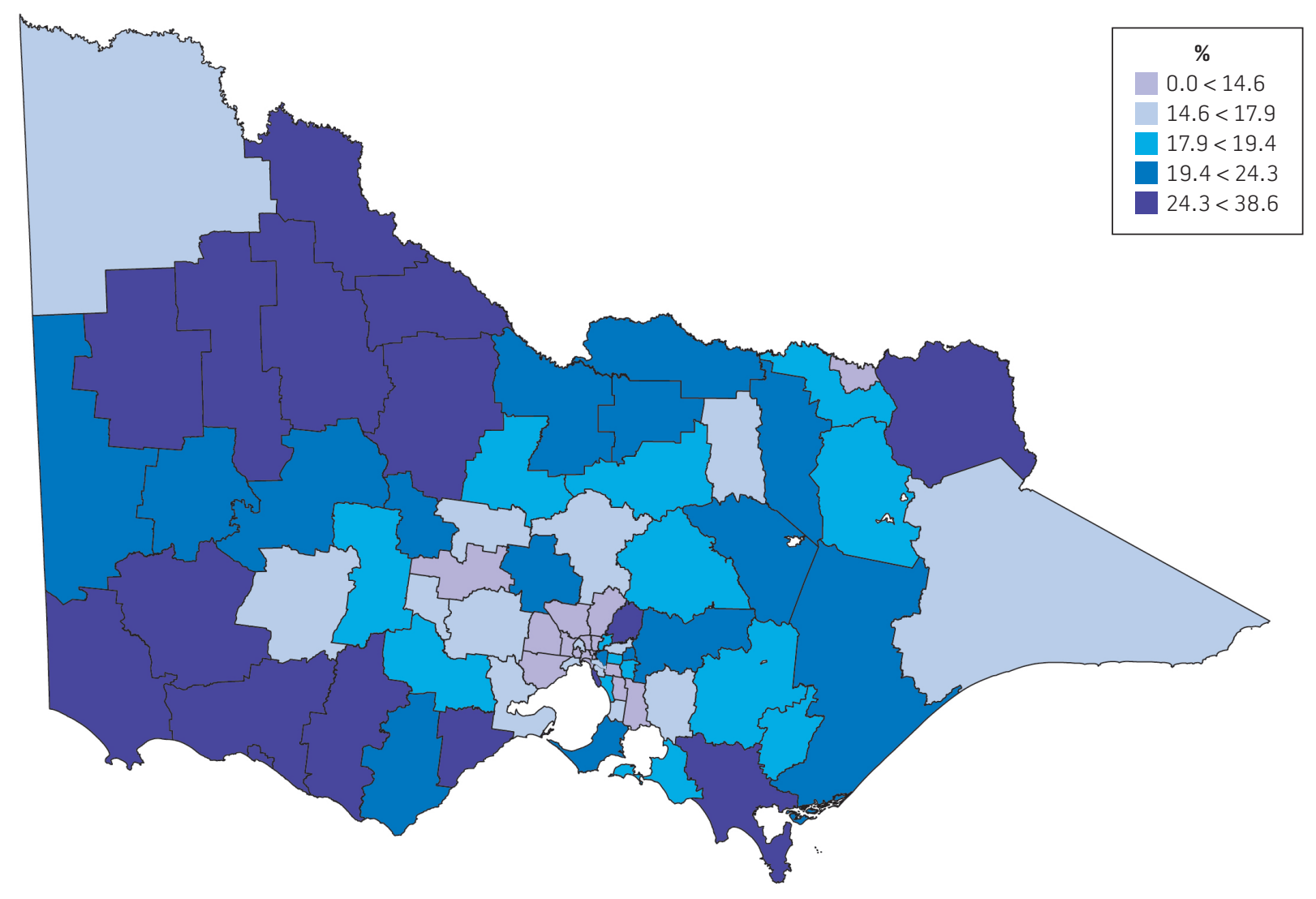

Figure 3: Participation rate, by LGA in Metropolitan regions, 2018

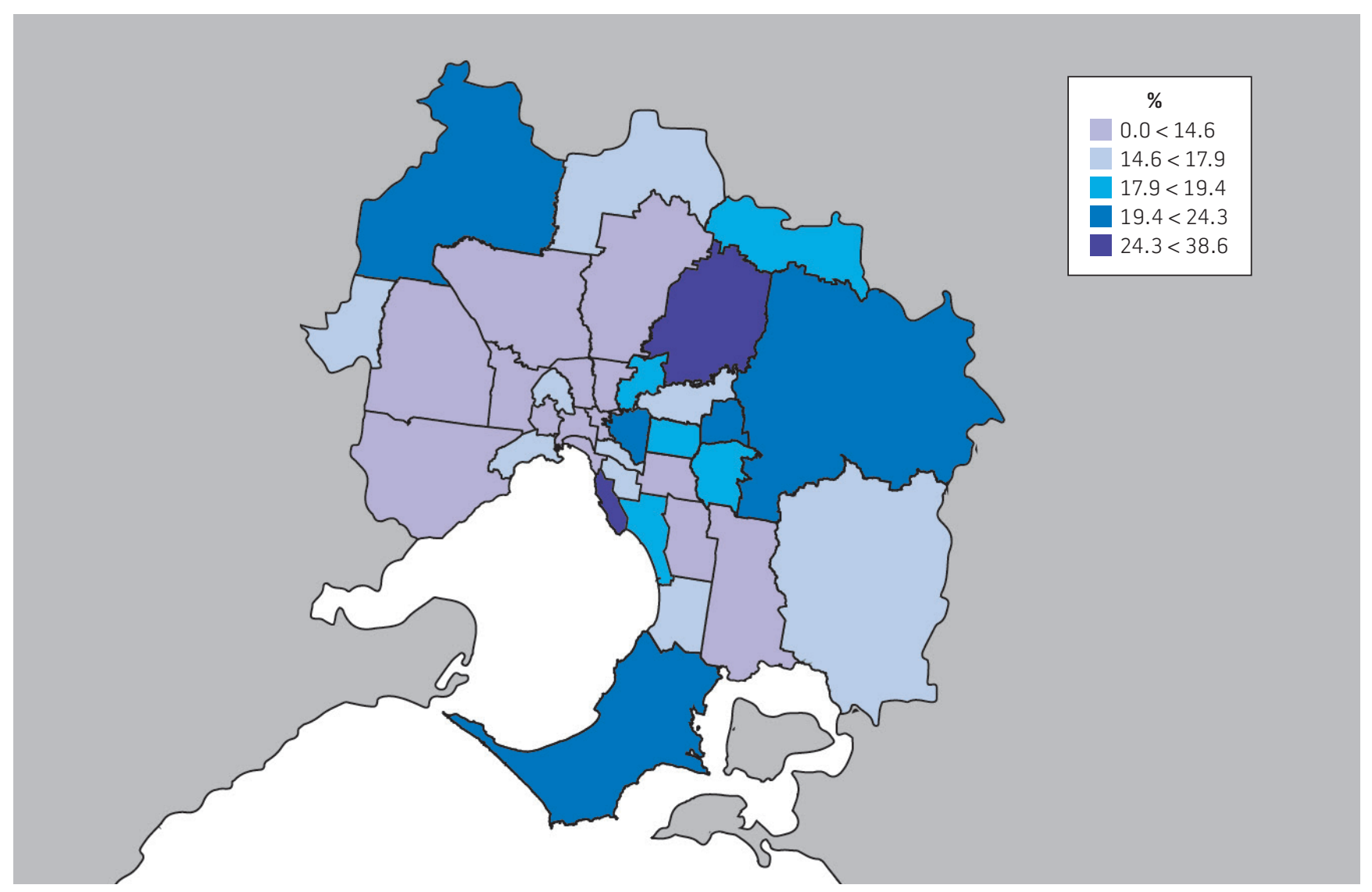


Table 1: Participation rates, 2018, Victoria: by Local Government Area

\begin{tabular}{|c|c|c|c|}
\hline LGA name & $\begin{array}{r}\text { Participation rate } \\
2018\end{array}$ & LGA name & $\begin{array}{r}\text { Participation rate } \\
2018\end{array}$ \\
\hline \multicolumn{2}{|l|}{ Metropolitan - growth } & \multicolumn{2}{|l|}{ Regional - other } \\
\hline Cardinia (S) & 13.7 & Alpine (S) & 15.9 \\
\hline Casey (C) & 10.3 & Ararat (RC) & 14.7 \\
\hline Hume (C) & 10.0 & Benalla (RC) & 14.5 \\
\hline Melton (S) & 8.2 & Buloke (S) & 30.5 \\
\hline Mitchell (S) & 13.0 & Campaspe (S) & 19.1 \\
\hline Whittlesea (C) & 9.3 & Central Goldfields (S) & 17.0 \\
\hline Wyndham (C) & 9.3 & Colac Otway (S) & 18.9 \\
\hline \multicolumn{2}{|l|}{ Metropolitan - other } & Corangamite (S) & 24.5 \\
\hline Banyule (C) & 16.4 & East Gippsland (S) & 13.7 \\
\hline Bayside (C) & 23.5 & Gannawarra (S) & 22.1 \\
\hline Boroondara (C) & 18.5 & Glenelg (S) & 20.2 \\
\hline Brimbank (C) & 6.4 & Golden Plains (S) & 16.1 \\
\hline Darebin (C) & 10.3 & Greater Shepparton (C) & 16.9 \\
\hline Frankston (C) & 14.5 & Hepburn (S) & 11.8 \\
\hline Glen Eira (C) & 14.4 & Hindmarsh (S) & 24.5 \\
\hline Greater Dandenong (C) & 5.1 & Horsham (RC) & 19.1 \\
\hline Hobsons Bay (C) & 13.4 & Indigo (S) & 16.0 \\
\hline Kingston (C) & 15.5 & Latrobe (C) & 15.6 \\
\hline Knox (C) & 15.3 & Loddon (S) & 22.6 \\
\hline Manningham (C) & 13.7 & Macedon Ranges (S) & 18.3 \\
\hline Maribyrnong (C) & 8.8 & Mansfield (S) & 18.5 \\
\hline Maroondah (C) & 17.1 & Mildura (RC) & 14.5 \\
\hline Melbourne (C) & 6.5 & Moira (S) & 16.5 \\
\hline Monash (C) & 11.1 & Mount Alexander (S) & 14.1 \\
\hline Moonee Valley (C) & 13.5 & Moyne (S) & 21.4 \\
\hline Moreland (C) & 8.9 & Murrindindi (S) & 15.8 \\
\hline Mornington Peninsula (S) & 18.8 & Northern Grampians (S) & 17.5 \\
\hline Nillumbik (S) & 23.6 & Pyrenees (S) & 15.9 \\
\hline Port Phillip (C) & 10.9 & Queenscliffe (B) & 24.1 \\
\hline Stonnington (C) & 13.8 & South Gippsland (S) & 21.6 \\
\hline Whitehorse (C) & 15.0 & Southern Grampians (S) & 25.4 \\
\hline Yarra (C) & 9.8 & Strathbogie (S) & 16.1 \\
\hline Yarra Ranges (S) & 17.0 & Swan Hill (RC) & 20.2 \\
\hline \multicolumn{2}{|l|}{ Regional - growth } & Towong (S) & 19.6 \\
\hline Ballarat (C) & 14.1 & Wangaratta (RC) & 17.4 \\
\hline Bass Coast (S) & 15.1 & Warrnambool (C) & 16.8 \\
\hline Baw Baw (S) & 16.4 & Wellington (S) & 16.6 \\
\hline Greater Bendigo (C) & 15.5 & West Wimmera (S) & 16.1 \\
\hline Greater Geelong (C) & 14.8 & Wodonga (RC) & 12.9 \\
\hline Moorabool(S) & 14.5 & Yarriambiack (S) & 25.7 \\
\hline Surf Coast (S) & 22.7 & end: $B=$ Borous & $y, S=$ Shire. \\
\hline
\end{tabular}

${ }^{1}$ Number of player registrations per 100 residents 


\subsection{About this research}

The Sport Participation Research Project has involved the analysis of data on organised sport participation in 12 major sports annually since 2015 . For 2018, two sports (golf and bowls) were unable to provide their participant data. Therefore, this report integrates and summarises sport participation across ten major sports and from 2015 to 2018.

This project reports on participation levels (numbers of registered participants and participation rates per head of population) and participation trends, for the Victoria population as a whole, and for various population segments.

The project aims to provide a reliable measure of organised sport participation in Victoria to inform planning, decisionmaking and investments for State Sporting Associations, all levels of government, funding bodies and sport participation promoters, particularly relating to participation initiatives and facility planning.

\section{ACKNOWLEDGEMENTS}

The Sport Participation Research Project 2015-2021 is funded by VicHealth and Sport and Recreation Victoria and is conducted by Professor Rochelle Eime, Ms Melanie Charity, Professor Hans Westerbeek, Dr Jack Harvey and Ms Jenna Fowlie (Victoria University and Federation University).

www.sportandrecreationspatial.com.au

The State Sporting Associations involved with this research are: AFL Victoria, Australian Sailing (Victoria), Basketball Victoria, Bowls Victoria, Cricket Victoria, Football Victoria, Golf Victoria, Gymnastics Victoria, Hockey Victoria, Netball Victoria, Swimming Victoria, and Tennis Victoria.

\section{Vichealth}

Victorian Health Promotion Foundation P0 Box 154 Carlton South Victoria 3053 Australia

$T+61396671333 F+61396671375$

vichealth@vichealth.vic.gov.au vichealth.vic.gov.au twitter.com/vichealth facebook.com/vichealth

VicHealth is committed to health equity, which means levelling the playing field between people who can easily access good health and people who face barriers, to achieve the highest level of health for everyone.

VicHealth acknowledges the support of the Victorian Government.

(c) Vic Health

August 2020

https://doi.org/10.37309/2020.PA894/1

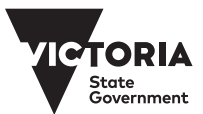

VicHealth acknowledges the Traditional Custodians of the land. We pay our respects to all Elders past, present and future. 